\title{
Development and implementation of the CIRCLE Framework
}

*Dr Donald Maciver ${ }^{\mathrm{a}}$, Cathleen Hunter ${ }^{\mathrm{ab}}$, Amanda J Adamson ${ }^{\mathrm{ac}}$, Zoe K Grayson $^{\text {ad }}$, Prof Kirsty A Forsyth ${ }^{\mathrm{a}}$, and Iona McLeod ${ }^{\mathrm{e}}$

${ }^{a}$ School of Health Sciences, Queen Margaret University, Edinburgh, United Kingdom; ${ }^{b}$ Physiotherapy Department, Royal Hospital for Sick Children, NHS Lothian, Edinburgh, United Kingdom; ${ }^{\circ}$ Occupational Therapy Department, Royal Hospital for Sick Children, NHS Lothian, Edinburgh, United Kingdom; ' $S$ Seech and Language Therapy, Royal Hospital for Sick Children, NHS Lothian, Edinburgh, United Kingdom; ${ }^{e}$ Additional Support for Learning Service, City of Edinburgh Council, Edinburgh, United Kingdom.

Corresponding author: Dr Donald Maciver. School of Health Sciences, Queen Margaret University, Edinburgh, Scotland, UK, EH21 6UU, Tel: +44(0)131 474 0000, Fax: +44(0)131 4740001 dmaciver@qmu.ac.uk

Acknowledgements: Thanks are due to the Head Teachers and staff from the participating schools. Thanks to the City of Edinburgh Council's Additional Support for Learning Service and to Martin Vallely, Professional Services Manager. 


\title{
Development and implementation of the CIRCLE Framework
}

\author{
We report the implementation of a new framework supporting teacher practice for \\ inclusion of children with disabilities in mainstream classrooms. Eight schools in one \\ Scottish authority took part. Questionnaire, focus group and interview data were \\ gathered. Results indicated that the framework was well-received and provided a useful \\ resource for class teachers. The framework was perceived as a feasible method for \\ supporting teachers and related personnel to think systematically about key issues \\ relating to children with disabilities in the classroom. It was suggested that provision of \\ a common language was supportive of collaborative working. Areas for revision \\ included a system of navigation and simplification in the framework manual.
}

Keywords: inclusion; disability; teaching; framework; children, collaboration, qualitative, implementation

\section{Introduction}

Children with disabilities are a significant part of the school population (Law, Rush, Anandan, Cox, \& Wood, 2012; NESSE, 2012; Taylor, Jick, \& MacLaughlin, 2013). Common difficulties, which include musculoskeletal disorders, sensory impairments, general and emerging developmental delay as well as specific and pervasive developmental difficulties such as autism spectrum disorders, put learners at increased risk for sub-optimal outcomes. They perform less well academically (Aron \& Loprest, 2012; Kauffman \& Landrum, 2009), have poorer outcomes in psychosocial domains (Chen \& Weikart, 2008; UNICEF, 2013), lower peer acceptance (Pereira, Cour, Jonsson, \& Hemmingsson, 2010; Raghavendra, Olsson, Sampson, Mcinerney, \& Connell, 2012), and are less likely to access further education (Aron \& Loprest, 2012; Whitehouse, Watt, Line, \& Bishop, 2009). It is of vital importance that effective interventions are in place. Classroom teachers are key individuals in this process. Teachers often have positive attitudes and are sympathetic towards learners with diverse needs; but many do not see themselves as having the skills, experience or resources to effectively support these learners (De Boer, Pijl, \& Minnaert, 2011; MacFarlane \& Woolfson, 
2013). We designed a framework to support classroom teachers in this area, which we tested in eight schools.

Inclusion of learners with disabilities is a concept that is open to significant discussion (Farrell, 2010; Koster, Nakken, Pijl, \& van Houten, 2009; Slee, 2014). Debate historically focussed on location i.e. general versus special school placement (Allan, 2010; Allan, 2012). Today, placement in general education is viewed as the preferable option in most cases, and inclusion is seen as a process involving acceptance, participation and achievement, as well as whole school and teacher transformation (Allan, 2010; Allan 2012; Florian \& BlackHawkins, 2011; Oh-Young \& Filler, 2015; Shogren \&Wehmeyer 2014). The literature on implementation of inclusion is diverse, but there is little reliable evidence about factors that make schools and classrooms more inclusive (Göransson \& Nilholm, 2014). Literature reviews indicate neutral to positive effects of inclusion, and although research supports the case for inclusion, it should be viewed with caution as the strength of the evidence is generally weak (Boyle, Topping, \& Jindal-Snape, 2013; Kalambouka, Farrell, Dyson, \& Kaplan, 2007; Ruijs \& Peetsma, 2009; Tiwari, Das, \& Sharma, 2015). How to "do" inclusion and what counts as evidence in this field is therefore a complex challenge (Florian, 2014).

A specific issue with available interventions is a focus on impairment or diagnosis. This is manifested as a "program for every problem" (Domitrovich et al., 2010) and has led teachers to report they can feel overwhelmed by the range of interventions and supports available (Florian, 2012). The complexity and sheer numbers of programs therefore makes selecting the right program for the right child at the right time difficult. Diagnosis driven interventions also miss the strong message that remediating the child's difficulties is divergent with philosophical and ethical principles of ensuring that learners are not reduced to their limitations (Florian \& Rouse, 2009). 
There are several inclusion-focussed frameworks, which have been developed to support and assist educators (Barrett, et al., 2015; Booth \& Ainscow, 2002; EADSNE, 2012; Florian \& Spratt, 2013; Shogren, McCart, Lyon \& Sailor, 2015). However, these have tended to focus on theoretical principles of inclusion (EADSNE, 2012), measurement of whole school inclusive practice (Booth \& Ainscow, 2002) or require a whole system approach (Shogren et al, 2015). What is missing from the literature is a framework where individual teachers have ready access to easily usable supports and strategies that can be applied to support children in the classroom; which additionally aids reflection on practice, and provides a common language and structure for sharing practice and collaboration.

Considering the above, and in response to a requirement for a general education focussed programme to support teachers to include learners with disabilities in primary (elementary) schools, we developed and implemented a framework to promote effective inclusive practices within general education. This framework represented an innovative collaboration between health professionals and education professionals aiming to develop ways of working and processes that would cross boundaries between the two communities ensuring best outcomes for learners. A summary of key issues considered in the design of the framework is provided below.

\section{Partnership and co-production}

A partnership was formed between university researchers, education and health professionals. This partnership, titled the Child Inclusion: Research into the Curriculum, Learning and Education (CIRCLE), undertook the development of the CIRCLE framework. Content for the framework was based on a review of literature and extensive qualitative research over a period of 2 years involving in-depth interviews with professionals from education, special education and health, and parents/carers. Content was refined using a process of cyclical 
review and co-production by the CIRCLE team. In addition to the academics and clinical researchers, the team included a Head (Principle) Teacher, Educational Psychologist, a range of Specialist Teachers, and senior representatives from children's occupational therapy, speech and language therapy, and physiotherapy services (details not reported in this paper but available from the author on request). This group of academics, educationalists and related services personnel, drawing on their experience and the qualitative research, identified practices that were considered realistic, appropriate and effective, and supported the development of materials that would have high levels of face validity and practicality.

\section{Beneficiaries}

CIRCLE is designed to support teacher practice in the area of inclusion of students with disabilities. However, the ultimate beneficiaries are students with disabilities aged approximately 5-12 years. We selected this group because physical, behavioural, developmental and learning disorders account for a significant proportion of learners with additional needs in Scotland (CFD, 2014) and internationally (Law et al., 2012; NESSE, 2012; Taylor et al., 2013).

\section{Theory}

Including theory as an element of design for any new framework is important as it enables us to build on existing knowledge and understanding of related concepts, which in turn can help guide the process of translating research into practice (Michie, Johnston, Francis, Hardeman, \& Eccles, 2008). Theoretical issues considered in the development of the CIRCLE framework included ecological perspectives (Lehohla \& Hlalele, 2012), dynamic systems theories (Kielhofner, 2008), and debate/discussion around the concept of "participation" from the World Health Organisation (WHO, 2007). These ideas stress that environmental components interact with children's impairments to influence participation and inclusion 
(Kielhofner, 2008; Lehohla \& Hlalele, 2012; WHO, 2007). These ideas reflect concepts from disability theory, in particular the social model of disability, which rejects the emphasis of individual impairment in favour of a focus on the disabling aspects of the environment, including culture, attitudes and institutions (Oliver, 2013). Dynamic systems thinking develops these ideas and focuses on the principle that aspects of a person and a person's environment are linked into a dynamic whole (Kielhofner, 2008), and that no single causal factor accounts for problems with participation and inclusion (Thelen, 2005). Rather, multiple possibilities account for these challenges, and by using a combination of strategies we attempt to address all of the factors contributing to the dynamic (WHO, 2007). This means that factors such as adults' behaviours, routines and structures within the school, and the physical and social environment are all important considerations. Given this focus, it was not our intention to produce a diagnosis specific framework. Instead, our focus is on behaviours which present challenges for inclusion and participation e.g. communication, attention, behaviour, motor skills or organisation which we termed "areas of challenge". This was combined with a structure grouping supports and strategies under three headings 'learning environment', 'routines and structures' and 'teacher approaches' (see table 1). The framework explicitly promoted the idea that the child's underlying issues are only part of the picture and that supports should be targeted at several factors, including surroundings (the physical and social environment), structures and routines within the class/school, and the behaviours and actions of adults. The framework provided strategies based on this set of ideas, including detailed lists for modifications to the learning environment, adaptations to structures and routines, and teacher led approaches.

\section{Collaboration}

Guides and processes for collaboration within the school and outside the school (e.g., with 
therapists or other health staff) were also provided within the framework. There is an endorsement in the literature for the need for improved collaborative working in schools and with partner agencies (Hemmingsson, Gustavsson, \& Townsend, 2007). Effective collaboration within the school and between school staff and partner agencies is of pivotal importance for the inclusion of children with disabilities (Hillier, Civetta, \& Pridham, 2010). Research highlights that education practitioners are influenced by strong organisational pressures, which may hinder partnership/collaboration (Hillier et al., 2010). A lack of interprofessional co-operation can result in a suboptimal service to the child (Hemmingsson et al., 2007). Collaborative working requires support and guidance to implement effectively (Quinn \& Mullally, 2008). A further issue concerns the concept of inclusive education as being predicated on 'special education' and focussed on provision by 'specialists' to minimise deviations from the 'norm' (Slee, 2011). This too can be a barrier to effective collaborative working. The CIRCLE framework was designed to re-enforce the idea that working with children of all abilities is the responsibility of everybody and promotes that all teachers can and should provide support for all children. However, collaborative working with specialists is required to support the inclusion of some children. This led to the development of the staged system of support underpinning the framework which begins with the 'Inclusive Classroom/school', moves to 'Areas of challenge and supports', then to the 'Tipping Point' (where teachers require assistance from specialists in order to meet the learner's needs), and then onto 'Effective Collaboration' where teachers work together with others (see table 1).

\section{Implementation science}

Interventions provided for use in general education must be easy to implement and adopt. Research linking implementation quality with outcomes suggests that positive results are more likely when the quality of the implementation is high (McLeskey \& Waldron, 2011). Change is also more sustained when teachers, school leaders and management are given an 
opportunity to influence ideas and integrate these into their practice (Ainscow \& Sandill, 2010). Supports must also be developed with current understanding of implementation science and knowledge of practice development and change management. The format, structure, presentation and implementation utility is therefore integral to success (McLeskey \& Waldron, 2011). The CIRCLE team considered the above and used several techniques for promoting high quality implementation, including a manual based on the CIRCLE framework (see table 1 and supplemental file 1) and optional training (see table 2). The framework was populated with supports and strategies from the results of a qualitative study, which investigated input regarding best practices used by teachers to support learners with additional support needs within the local area. Through the processes of review of drafts of the emerging framework, teachers, education leaders and management had the opportunity to influence development.

Implementation of the CIRCLE framework involves teachers (and other education staff) considering the contents, in relation to their work context and existing school structures. The first step of the framework provides advice and strategies for teachers 'working towards an inclusive classroom' (inclusive classroom strategies). The second step encourages teachers to consider which of the overarching 'areas of challenge' are most relevant, if further support for an individual child is required, and to consider their practice in relation to suggested supports and strategies for that 'challenge'. The next step is the 'tipping point' when, having already implemented classroom and individual strategies, teachers consider whether a referral for further support is required. The final section of the framework outlines key points to support collaborative working with others, either internal or external to the school. The framework is designed to support existing practice (providing a single point of first level supports and strategies) and improve discussion and sharing of practice ideas by using a consistent structure and terminology. As it supports existing practice, it should not be 
onerous or time-consuming to use, but should form part of existing practice. An overview of the aims and content of the framework is provided in table 1. 


\section{Table 1. Overview of the CIRCLE framework*}

\section{Aims of the CIRCLE framework:}

- Share ideas, advice and strategies for improving the engagement and achievement of learners who have additional needs

- $\quad$ provide a quick, accessible reference for teachers, with practical solutions

- promote a learner-centred approach and effective inclusive practice

- describe how to request external support if challenges cannot be fully met within a class or school

- $\quad$ emphasise the need for successful collaborative working

- $\quad$ provide a reflective framework and training resource

\section{Inclusive Classroom/School section}

- This section provides an overview of teaching methods, ideas and techniques focusing on the classroom and school environment.

- It delineates nine dimensions of an inclusive classroom/school along with practical examples.

\section{Areas of Challenge and Supports section}

Supports and strategies for common areas of areas of need (e.g. communication skills, motor skills, organizational

skills or behaviour) are provided. Suggestions for supports and strategies are organized in three categories:

- Learning Environment: practical supports and strategies directed at making changes to the physical and social environment. These include physical adaptations (e.g. providing individual workspaces), sensory adaptations (e.g. quiet areas) and social adaptations (e.g. arranging the class seating to promote interaction).

- $\quad$ Structures and Routines: supports and strategies for consistent application of activities, resources or supports. This allows children to develop an understanding of expectations and procedures. The supports and strategies include the use of regularly timetabled activities (e.g. small group activities) and consistent use of resources (e.g. clear and organised worksheets).

- Teacher Approaches: supports and strategies to enable either a child's actions or understanding. Strategies include communication (e.g. simplify and shorten instructions), supporting completion of tasks (e.g. prompting), motivation (e.g. praise) and self-management (e.g. taking a calm approach).

\section{Tipping Point section}

- This section contains information on when teachers make the decision to seek extra support, either within a school, or in the form of referral to a therapist, partner service or other agency.

- It also discusses what teachers do before they reach this point.

- A decision matrix is provided.

\section{Effective Collaboration section}

- Information on joint working between school staff and therapists, partner services or other agencies is provided in this section.

- It also gives suggestions on what effective, successful collaboration may look like, and how collaborative working can be used to meet learners' needs.

*The CIRCLE framework is presented in a 115 page manual. 


\section{Methodology and methods}

No aims to evaluate impact on learners were identified at this stage, and no quantitative data were collected. The main aim was to test feasibility and teachers perceptions of the framework prior to further dissemination. The study had therefore three aims: (1) to explore satisfaction among school staff, (2) to explore perceived impact on staff, and (3) to gather recommendations for modification.

\section{Context}

This work formed part of an overarching initiative tasked with improving outcomes for learners with disabilities in the locality. This was completed in one City in Eastern Scotland. In Scotland, the Children and Young People (Scotland) Act 2014 assumes general education for all learners (from the age of 5 years), thus most children with disabilities are in general education (CFD, 2014). Provision for learners varies by location, but practices follow a national model titled "Getting it Right for Every Child (GIRFEC)" where all practitioners working with a child have a duty to identify and address their needs, sharing information and working in partnership with others if required (Ainscow \& Sandill, 2010). Under GIRFEC, the needs of learners are identified and met by the classroom teacher, with support from specialist additional support for learning (ASL) teachers based in each school and agencies external to the school (e.g. visiting specialist ASL teachers, occupational therapists, speech and language therapists, or psychologists) as required. For children with very complex needs, highly specialist support is available, e.g. segregated schooling or split placements between general and special schools, though these form a very small percentage of the overall provision (Scottish Government, 2010a). At any point, multi-agency meetings may take place to meet statutory requirements and to support the planning process (Scottish Government, 2012). 


\section{Sample}

The study was conducted in a city with a population of approximately 440,000 and approximately 25,000 learners aged 5-12 years (Scottish Government, 2010a). Schools were selected with assistance from the Local Education Authority to ensure representation of those within the area in terms of size and socioeconomic deprivation as identified using the Scottish Index for Multiple Deprivation (Scottish Government, 2010b). All schools used in the study recorded numbers of learners as having additional support needs (e.g. learning disability, autism spectrum disorder, motor disorders etc.) in line with national averages (Scottish Government, 2010a). School staff (e.g. teachers, management) and non-school staff (e.g. visiting specialist ASL teachers) with responsibility for liaising and collaborating with teachers, were the participants. A convenience sample of eight schools agreed to trial the framework.

\section{Ethics and Consent}

Following guidelines by the British Educational Research Association (BERA, 2011), permission to conduct the study was gained from the Local Education Authority and approvals for access were secured from each participating school. Although participants could not opt out of using the framework, as this had been negotiated at school management level, we were mindful of coercion, and participants were assured they could withdraw from the study evaluation elements at any time and that their views were confidential. Written informed consent was gained from any participant who took part in a focus group, interview or completed a questionnaire.

\section{Deployment and training}

The framework was designed so that it could be used without any introductory training i.e. as 
a standalone document. However, to support initial implementation, the schools were offered a 'menu' of optional introductory training (see table 2). It was not the intention to train to fidelity, but rather to give the staff an overview (along with more in-depth support if requested by the Head Teacher).

Table 2. Training offered to schools

\begin{tabular}{|c|c|c|}
\hline Modality & Delivery & Description \\
\hline Manualised materials & $\begin{array}{l}10 \text { master copies per school to } \\
\text { be photocopied as required }\end{array}$ & 115 page manual covering the framework. \\
\hline Overview sessions & Presentation & $\begin{array}{l}\text { Brief introductory session (for class } \\
\text { teachers, support for learning teachers, } \\
\text { learning assistants, and senior } \\
\text { management). }\end{array}$ \\
\hline Problem solving sessions & Group or individual & $\begin{array}{l}\text { Individual sessions with staff around using } \\
\text { the framework or sessions with small } \\
\text { groups of staff who are experiencing } \\
\text { particular learner challenges. }\end{array}$ \\
\hline In-class sessions & $\begin{array}{l}\text { Observation and in-class } \\
\text { support }\end{array}$ & $\begin{array}{l}\text { In class guidance for individuals on } \\
\text { supports and strategies and using the } \\
\text { framework. }\end{array}$ \\
\hline
\end{tabular}

The Head (Principal) Teachers determined the amount of input for their school. The minimum provided was an introductory session along with distribution of physical copies of the framework manual (see supplemental file 1). Most schools requested more input, as they perceived this as a continuing professional development opportunity for their staff.

\section{Data collection}

Staff used the framework for a period of 6-8 weeks (within the local area the school year is divided into terms of approximately 10 weeks). Data were gathered via questionnaires, interviews and focus groups. Questions across all data gathering methods focussed on staff's perceptions of the following: How has the CIRCLE framework been used in school? Have education staff made any changes when supporting learners as a result of introducing the 
CIRCLE framework? Have there been any changes in collaboration and communication between staff since introducing the CIRCLE framework? What changes to the CIRCLE framework and CIRCLE manual would be beneficial?

Questionnaires asked staff to provide written comments in free text boxes. Interviews took place with single individuals. Focus groups took place with groups of staff (maximum of 6 participants). The decision to offer an individual interview or participation in a focus group was based on school staff availability and the researchers' perception of how individuals might react in a group (e.g., a newly qualified teacher might feel they had to modify their responses in the presence of a Head Teacher). In order to maintain cohesion across the project, the focus groups were co-run (minimum 2 researchers) and interviews were observed by another researcher. All interviews and focus groups were audio recorded. Written informed consent was received from all participants.

A team of researchers and research assistants completed the data collection. All of the researchers had received training in qualitative methodology. In addition to their research role, each of the researchers was experienced in providing specialist support to learners in a variety of education settings. A researcher with expertise in qualitative research and intervention development led the research and oversaw the data collection and analysis.

\section{Analysis}

Focus groups, interviews and questionnaires were transcribed verbatim. All data were qualitative so analysis followed the theoretical perspective of thematic analysis (Patton, 2002), using a coding method (Creswell \& Miller, 2002). Transcripts were read in detail, word by word, to derive initial coding. An open coding procedure was used to identify text that captured key thoughts or concepts (Creswell \& Miller, 2002). Themes were derived to express the content of the codes (Patton, 2002). Analyst triangulation (the three researchers 
and research lead) and team coding allowed for inter-observer reliability checks of the coding (Whittemore, Chase, \& Mandle, 2001). The prolonged fieldwork allowed for ongoing analysis of the data, which improved the trustworthiness of the results. Additional notes and memos made by the researchers were also discussed during team meetings during analysis. Themes were confirmed through peer debriefing with a group of staff from the participating schools. This form of member checking helped add validity to the results.

\section{Results}

In total, 163 staff returned a questionnaire ( $72.12 \%$ response rate) (see table 3 ) and 27 staff (see table 4) took part in the focus groups or interviews. 
Table 3. Schools, questionnaire return rate, staff designation.

\begin{tabular}{|c|c|c|c|c|c|c|c|c|c|}
\hline School & School A & School B & School C & School D & School E & School F & School G & School H & \\
\hline Approx. learners on school roll & 200 & 200 & 300 & 300 & 400 & 400 & 500 & 500 & Totals \\
\hline Participants & 34 & 24 & 20 & 23 & 31 & 40 & 35 & 19 & $226($ mean 28.2$)$ \\
\hline Questionnaires returned (\%) & $21(61.8 \%)$ & $23(95.8 \%)$ & $12(60 \%)$ & $19(82.6 \%)$ & $12(38.7 \%)$ & $32(80 \%)$ & $26(74.3 \%)$ & $18(94.7 \%)$ & $163(72.1 \%)$ \\
\hline
\end{tabular}

Staff designations (returned

questionnaires)

\begin{tabular}{|c|c|c|c|c|c|c|c|c|c|}
\hline Head / Principle Teacher* & 1 & 1 & 0 & 3 & 2 & 1 & 2 & 3 & 13 \\
\hline Support for Learning Teacher** & 1 & 1 & 1 & 0 & 0 & 1 & 1 & 0 & 5 \\
\hline Class Teacher & 11 & 15 & 9 & 16 & 8 & 18 & 20 & 15 & 112 \\
\hline Role not specified & 2 & 0 & 1 & 0 & 1 & 2 & 0 & 0 & 6 \\
\hline Learning Assistant $* * *$ & 6 & 6 & 1 & 0 & 1 & 10 & 3 & 0 & 27 \\
\hline
\end{tabular}

Note. $*$ Includes teachers involved in senior management within the school; **Teachers, specialist in supporting children with additional needs, who is based within the school; ***Non-qualified staff who support specific learners within the class under the direction of the class teacher

Table 4. Interview \& focus group participants.

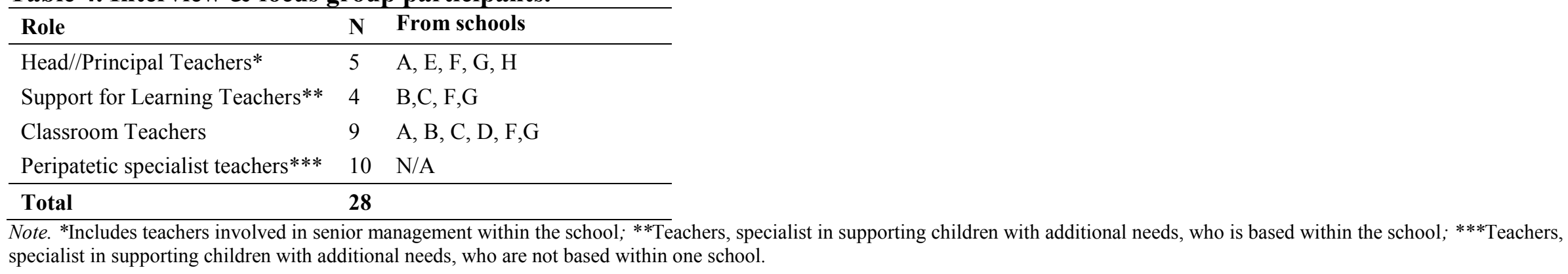




\section{Themes}

Transcribed questionnaires, interviews and focus groups provided qualitative data for our analysis. The format for display of results will therefore be as themes. To maintain anonymity the schools have been aggregated in the analysis, and quotes are not linked to specific schools.

The themes are: (1) the perceived utility of the CIRCLE framework, (2) the perceived impact on staff culture change, (3) the perceived impact on staff collaboration and communication, (4) perceived outcomes for learners, (5) issues with CIRCLE framework.

\section{Perceived utility of the CIRCLE framework}

The perceived utility of the framework was high from questionnaire responses, and confirmed in focus group and interview responses. This was particularly salient for school leaders, who reported being inundated with potential improvement programs, and therefore reviewed carefully the decision to support implementation:

As a gate keeper, I've let this through the gate and I want us to use it: this is quite high on my level of priorities as a useful tool. (Head/Principal Teacher: Focus Group)

Teachers suggested that the framework was helpful in increasing understanding of learners' needs and how to meet these differing needs in context. Teachers reported a change in their understanding of different areas of challenge and that overall the CIRCLE framework manual was a source of useful and practical ideas:

It's a first port of call if you've got a concern about a child...I see this [the CIRCLE framework manual] as a good place to start for any class teacher. (Classroom Teacher: Interview)

The majority of the participants responded positively to the framework, and saw uses for it in 
complementing existing procedures such as identifying needs or writing plans. Questionnaire responses indicated that the section related to 'Areas of Challenge and Supports' was referred to most frequently and described as being most commonly used by teachers. The usability of the framework manual was positively highlighted by many, including the clear layout and accessibility of the print materials:

It provides a quick reference point, so less time spent researching and more time addressing issues. It's really helpful to have a process outlined for you in a manageable, understandable and comprehensive form. (Classroom Teacher: Interview)

Less experienced staff and newly qualified teachers (NQTs) in particular were perceived as key beneficiaries:

It has been the NQTs who have shown most interest. and they've gained quite a lot from it; the probationers [NQTs] don't know all the strategies, so find it useful. (Head/Principal Teacher: Focus Group).

\section{Perceived impact on staff}

Some participants reflected that using the framework could potentially be a means of facilitating culture change in schools:

After using CIRCLE I have a deeper understanding of the difficulties and stresses and challenges some children experience, therefore I can offer a varied approach and support pupils with methods that can help them cope with their difficulties. (Class teacher:

Questionnaire)

I found CIRCLE very helpful to understand how a specific child in my class learns and the difficulties they may face. It will help me to adapt my teaching style and to alter a task to be more sympathetic to more children's needs. (Class Teacher: Questionnaire)

Some participants discussed that teachers were predisposed to organise support for learners by viewing learners with additional needs as "a specialist" responsibility. They reflected that 
this could result in teachers assuming that "a specialist" member of staff would step in with solutions. They suggested that the CIRCLE framework could be a way of facilitating different ways of thinking by teachers around their role, and of encouraging reflection on the strategies available for class teachers to use before seeking advice and support from specialist teachers:

[The CIRCLE Framework gives teachers] a better idea of who to go to, but also what could be done in the class to address any difficulties before referring onwards. (Class teacher: Questionnaire)

It gives me a cohesive structure to follow/get advice from, it empowers me. (Class teacher: Questionnaire)

As a probationer [newly qualified] teacher, the resource [the CIRCLE framework] will help to give me clear guidelines and ideas for supporting pupils. (Probationer teacher: Questionnaire)

Support for the above findings was also evidenced in school leaders' responses indicating that the framework could be used to influence class teachers to focus on what they could try within their class, before seeking support:

I see this [the CIRCLE framework] preventing a lot of unnecessary referrals. Teachers identify and use the strategies, so that we don't go to Pathway 3 or even Pathway 2 [specialist support]. (Head/Principal Teacher: Focus Group)

One Support for Learning teacher felt that the use of the framework had resulted in class teachers successfully dealing with issues within their class without requiring support from specialist teachers:

[As a result of using the CIRCLE framework] teachers have managed these children very well...these two children have been supported in class [by the class teachers] and did not need any additional input. (Support for Learning Teacher: Focus Group). 
Specialist teachers also commented on the utility of the materials for potentially upskilling and encouraging classroom teachers to take responsibility for provision for learners and to think differently about the types of support that could be provided:

The teachers were saying "we're doing all these strategies"...but once I took in a CIRCLE document [the CIRCLE framework manual] and went through it and said, "how could we add to that" they said "oh yes, we could do this". So I thought it was really good using it to help focus them to change their way of looking at things to "I'm doing this, but I could do it better or in a different way". (Support for Learning Teacher: Interview).

\section{Perceived impacts on collaboration and communication}

There was a very clear consensus by participants of the perceived value of the framework in terms of improving collaboration and communication between professional staff. This was mentioned frequently in questionnaire responses and in the interviews and focus groups:

CIRCLE encourages collaborative working; this does and will impact positively on pupils' [learners'] progress. (Head/Principal Teacher: Interview).

Participants highlighted the benefits of using a common language and framework, which they suggested could improve understanding, communication and collaboration:

[Using the CIRCLE framework manual] we're all sort of singing from the same book, because it's integrated there is less danger of it being forgotten. It's true that if we all know that we are doing things in a similar way, and working towards a common goal, it's helpful. (Head /Principal Teacher: Focus Group)

Several participants also reported that the format of the CIRCLE framework manual was easy to use for sharing practice with others and provided materials that were useful for recording and sharing information: 
The CIRCLE strategies [from the CIRCLE framework] ensure that we have a record of the support given to her [learner] and will inform her transition to the next year stage. (Class Teacher: Interview)

\section{Other impacts}

Many participants commented that as a result of the CIRCLE framework (training and using the CIRCLE framework manual) they felt they had increased awareness of inclusion, areas of challenge, supports and strategies, referral processes, and collaboration, which might lead to benefits for learners in their classes. For example, in terms of increasing understanding of learners' needs and related supports, many class teachers reported that they thought they had a better understanding of the stresses and challenges that some children experience and would now feel more confident to provide support. However, these improvements were commonly identified as tentative and speculative due to the recent implementation. Nevertheless, the teachers from the focus groups and interviews were positive about the potential to improve outcomes, and a few already had positive examples:

I think it's pretty early stages but I can definitely say that with the two teachers who have used CIRCLE [the CIRCLE framework] it's given them food for thought. So I could say that even in a small way it has now impacted some children in the class. (Support for Learning Teacher: Focus Group)

Some participants were able to highlight particular strategies from the framework that they had used which had resulted in improved performance for learners:

We used the Teacher Led Approaches from the Attention and Concentration checklist and supported these with the Structures and Routines from the same list...[the learner's] concentration and attention have improved and are no longer the main issues. (Class Teacher: Interview)

Teachers also suggested that the common language and structure of the CIRCLE framework could potentially improve discussions around support for learners who were enrolled at more 
than one setting (e.g. learners who have a split-placement between special and mainstream schools) and when learners transition to a new class or school.

\section{Issues with the framework}

A key aspect of the study was to test feasibility and make recommendations for alterations. Participants reported that parts of the framework manual were too complex. The overall length of the CIRCLE framework manual was criticized by some participants, and it was suggested that it would benefit from an improved means of navigating the sections. Other participants reported that they had started using the framework manual informally for recording strategies already used and suggested that versions designed for note taking/photocopying should be developed. Although the framework was designed partly to support collaborative working between teachers and other professionals, it was suggested that it would be beneficial to have a section focussing on collaboration with parents and carers:

If we could use the resource [the CIRCLE framework manual] with parents... I think it would be good to have something where we could...show we are doing this and this. (Class teacher: Focus Group)

In addition to issues with the structure and content of the framework, participants also provided information useful to future implementation:

I think a good way forward would be for schools to have their own in-house training on using the CIRCLE document [CIRCLE framework manual], so that every member of staff in every school is familiar with it. (Class teacher: Focus Group)

Specific suggestions included whole school in-services around the framework; the use of case studies demonstrating the use of the framework for sharing within and between schools; incorporating training sessions into the existing professional development sessions; and setting up specific interest groups within schools around the framework. 


\section{Discussion}

The objectives of this study were to assess the utility of the CIRCLE framework, explore staff satisfaction and gather recommendations for modification. Our findings indicate that participants were supportive of the framework and found it relatively straightforward to understand and use. The findings were aggregated across all staff as, although an interesting concept for future research, it was beyond the scope of this study to investigate differences between staff groups. The results highlighted that the framework dovetailed with their own practice and thinking. The results are tentative, as the schools had only been using the framework between 6-8 weeks. However, many of those who gave feedback suggested that the CIRCLE framework could have a positive impact in terms of promoting teacher responsibility for providing initial strategies within an inclusive classroom and reducing reliance on specialist support, as well as benefits for collaboration between staff. In particular, many participants commented on their increased awareness of areas of challenge, supports, strategies, the referral process, and collaborative working.

It is likely that a key mechanism for reported impacts was a product of focussed discussions on inclusionary practice. CIRCLE provides this but it is possible to imagine that a different framework, with different content, might lead to similar outcomes. However, how to facilitate discussion on inclusionary practice and how to translate this into real practice, continues to be an ongoing area of debate in the literature. A number of different aspects appear to be important in achieving this, and the factors built into the CIRCLE framework provide a guide for these key considerations. It is suggested that developmentally appropriate and organised classroom materials within a well-structured program is one of the key aspects for effective inclusion (Simpson, Peterson, \& Smith, 2011). Our findings also provide support and insight into the theoretical perspectives that drove the development of the framework. Descriptions of supports, strategies and approaches, combined with theoretical underpinnings 
of additional support practices are often too superficial to infer conclusions and allow comparisons (Ruijs \& Peetsma, 2009). This means that more work is required in “conceptualising the options of inclusive education" (Lindsay, 2007). A framework underpinning inclusion approaches must therefore be clearly outlined in order to develop policy and practice coherently. A key strength of the CIRCLE framework is the coordination and integration of the program components.

The findings from implementation of the framework revealed that participants perceived that CIRCLE had the potential to change culture and attitudes of class teachers. The framework was designed with the intention of re-enforcing the idea that working with children of all abilities is the responsibility of everybody, not just specialists (Blanton \& Pugach, 2007; Florian \& Rouse, 2009). Several studies show that teachers' attitudes shape the promotion of inclusion (Forlin \& Chambers, 2011), and that training is particularly important in developing positive attitudes and practices (Gwernan-Jones \& Burden, 2010). Florian and Rouse (2009) propose that teachers should be encouraged to view inclusion as an approach for all, rather than being specialist, different or unusual. CIRCLE provided a framework to support intervention, which did not appear "specialist" in its content, using language that did not resort to diagnosis driven terminology. The promotion of teacher-led classroom and other environmental modifications meant that the framework was perceived to challenge teaching cultures focussed on the individualised supports provided by specialists outside the classroom. This change in focus is beneficial as it de-stigmatises the practice of adapted education (Eisenman, Pleet, Wandry, \& McGinley, 2011), again making inclusion a "normal" practice. This was reflected by Szumski and Karwowski (2014) who found that reducing the role of special education teachers in inclusive classrooms can result in positive outcomes.

In our study, some participants reported that the framework provided a comprehensive foundation, and that they found it useful for providing suggestions of first level supports and 
strategies, when they would previously have thought that they would be unable to manage a learner's additional needs themselves. School leaders and educators with a primary responsibility for providing additional support also reported that the framework was potentially beneficial in supporting class teachers to implement useful strategies before involving others.

In the framework, by structuring supports and strategies under "Teacher Led Approaches", "Structures and Routines", and "Learning Environment", teachers were encouraged to shift their focus from thinking about changing a learner, towards considering how to change themselves and the environment. Routinely focussing on the environment encourages staff to decentralise the child's difficulties as the main problem (Black-Hawkins, Florian, \& Rouse, 2007; Florian \& Rouse, 2009; Maciver et al., 2018). This thinking eschews a deficit or medical model (where the problems are viewed as emanating from the child) and helps practitioners to apply a social model of disability (where we understand that the environment is a significant contributor). Developing theoretical understandings and building application of theories into practice are fundamentally important for teacher development in inclusion (Florian, 2012), especially considering the diverse perspectives which exist on the subject. The perceived influence of the CIRCLE framework on collaboration and communication can be explained in a number of ways. Firstly, the framework provides a consistent approach to collaborative working within the locality, where professional responsibilities and boundaries are clear, rather than one which varies within and between schools and teachers. Additionally, it provides formal structures for sharing practice together with a consistent shared language, all of which support more effective communication over time, because of the commonality in approach. Unlike other inclusion tools, the CIRCLE framework has been designed with a specific aim of supporting collaboration with colleagues both within and outside the school. With respect to the benefits for collaboration, we note the 
broad literature highlighting the importance of collaboration (Hemmingsson et al., 2007) and the benefits of improved partnership working (Eisenman et al., 2011). The positive feedback noted on the utility of a shared language speaks directly to previous research noting challenges with articulating practices, and use of terminology (Hunter et al., 2013). It is recognised that the terminology used within the CIRCLE framework could mean different things to different people, and that supports and strategies can be conceptualised and implemented in different ways. However, by using this consistently throughout and between schools in one area, it is hoped that it will provide a common language to support sharing of and reflection on practice. A consistent framework and language can be particularly beneficial where joint working is required to achieve goals (Hemmingsson et al., 2007).

Other frameworks do exist to support the inclusion of children with additional support needs (Barrett, et al., 2015; Booth \& Ainscow, 2002; EADSNE, 2012; Florian \& Spratt, 2013; Shogren et al., 2015). For example, the Index for Inclusion (Booth and Ainscow, 2002) has an explicit focus on whole school processes, enabling senior management to lead a school through cycles of change and develop an inclusive school development plan. Whereas the CIRCLE framework, although benefiting from whole school leadership, may also be used by individual teachers in implementing and discussing classroom strategies, and has a clear focus on collaborative working with health colleagues around the needs of children with disabilities.

Although the results were largely positive, a key aim of this study was to gather recommendations for modification to the CIRCLE framework. The main areas highlighted as requiring attention were: navigation of the resource; complexity of 'the Tipping Point' section; length of the CIRCLE framework manual; lack of structures and photocopiable templates for formally recording input using the framework; and the need for a section on 
collaborating with parents. This was fed back to the CIRCLE team, which led to further review and revision of the framework.

The CIRCLE team initially thought that navigation of the resource was clear; however it was apparent from the results that teachers were mainly using individual sections rather than working through the resource in a staged way. For example, the participants reported most commonly using the 'Areas of Challenge' section, which provided checklists of strategies to support an individual child, rather than first ensuring that they had set up their classroom to be inclusive of all learners. This focus on the individual child, rather than on adapting the environment to be suitable for all, is at odds with the overall principles of the CIRCLE framework and current thinking (Morningstar, Shogren, Lee, \& Born, 2015). As a result the 'Inclusive Classroom' section was expanded to make it more user friendly, including checklists similar to the 'Areas of Challenge' section, and is now clearly highlighted as the first step in the framework. Photocopiable tools and templates were also developed by the CIRCLE team to support use of the framework, providing easy ways of recording input and navigation to the most appropriate 'Area of Challenge', when support over and above that provided from an inclusive classroom is required. The feedback also led to streamlining the CIRCLE framework manual, decreasing the length and reducing the complexity of sections such as the 'Tipping Point'. An additional section was developed in conjunction with parent/carer advocacy groups to support collaboration with parents/carers, as it was agreed that this is crucial to increasing inclusion and achievement of children in school (Castro et al., 2015). A further change to the CIRCLE framework manual, was revision of the 'Introduction' to clearly outline the CIRCLE framework as a staged system of support, starting with setting up an inclusive classroom. Following a further cyclical process of production, review and refinement of drafts, the final CIRCLE Framework was produced and has been successfully implemented within the locality schools. 
This study was carried out in one Scottish City, however, as the CIRCLE framework was designed to be used within a school's existing structures, it has relevance across other geographical contexts where class teachers support children with disabilities in general education settings.

\section{Limitations}

There are some limitations, which should be discussed. Firstly, although the framework manual is designed to be used without specific training, the differing intensity and format of training requested by the schools in this study may have affected participants' perceptions of the CIRCLE framework and the way it was used. Secondly, data regarding impact on learners were collected only via participants' perceptions; no formal data were gathered on child outcomes. Further research should focus on prospective evaluation of children's outcomes using a controlled design. Thirdly, the short duration of the study allowed little time to judge the impact of the framework with regard to working in sustained partnerships with colleagues external to the school. This will be a consideration for future studies.

\section{Conclusions}

The results of our study suggest that implementation of the CIRCLE framework helped support education staff to better understand learners' needs, reduced unnecessary referrals to specialist services, and aided collaborative practice. The combined findings from the different components of this study suggest that changes in attitudes and behaviours were beginning to occur. Those providing feedback after $6-8$ weeks perceived that the framework had a positive impact on their practice. They reported beginning to think and do things differently, suggesting that implementation of the framework was a feasible method of encouraging teachers and related personnel to think systematically about key issues relating to children with disabilities in the classroom. Although the framework was found to be easy to use, 
important information was gathered which informed further development. As a result, an updated version of the framework was produced. One unique and attractive feature of the CIRCLE framework is that it was developed in close collaboration with expert practitioners who were given the option of participating in the development and finalisation of the framework. Further research is now required to measure impact on outcomes relevant to inclusion, participation, and achievement of learners. 


\section{References}

Ainscow, M., \& Sandill, A. (2010). Developing inclusive education systems: the role of organisational cultures and leadership. International Journal of Inclusive Education, 14, 401-416. doi:10.1080/13603110802504903

Allan, J. (2010). Questions of inclusion in Scotland and Europe. European Journal of Special Needs Education, 25, 199-208. doi:10.1080/08856251003658710

Allan J. (2012). The inclusion challenge. In T. Barow \& D. Ostlund (Eds.), Bildning for alla! En pedagogisk utmaning (Education for all! A pedagogical challenge) (pp.109-120). Kristianstad, Sweden: Kristianstad University Press.

Aron, L., \& Loprest, P. (2012). Disability and the education system. The Future of Children, $22,97-122$.

Barrett, L., Beaton, M., Head, G., McAuliffe, L., Moscardini, L., Spratt, J., \& Sutherland, M. (2015). Developing inclusive practice in Scotland: the National Framework for Inclusion. Pastoral Care in Education, 33, 180-187. doi:10.1080/02643944.2015.1070896

Black-Hawkins, K., Florian, L., \& Rouse, M. (2007). Inclusion and Achievement in Schools. London, England: Routledge.

Blanton, L. P., \& Pugach, M. C. (2007). Collaborative programs in general and special teacher education. Washington, DC: Council of Chief State School Officers.

Booth, T., \& Ainscow, M. (2002). Index for inclusion: Developing learning and participation in schools. Bristol, England: Centre for Studies on Inclusive Education.

Boyle, C., Topping, K., \& Jindal-Snape, D. (2013). Teachers' attitudes towards inclusion in high schools. Teachers and Teaching, 19, 527-542. doi:10.1080/13540602.2013.827361 
BERA [British Education Research Association] (2011). Ethical guidelines for educational research: 2011. Retrieved from: https://www.bera.ac.uk/researchers$\underline{\text { resources/publications/ethical-guidelines-for-educational-research-2011 }}$

Castro, M., Expósito-Casas, E., López-Martín, E., Lizasoain, L., Navarro-Asencio, E., \& Gaviria, J. L. (2015). Parental involvement on student academic achievement:A metaanalysis. Educational Research Review, 14, 33-46. doi:10.1016/j.edurev.2015.01.002

Chen, G., \& Weikart, L. A. (2008). Student background, school climate, school disorder, and student achievement: An empirical study of New York City's middle schools. Journal of School Violence, 7(4), 3-20. doi:10.1080/15388220801973813

CFD [Children and Families Directorate] (2014). Children's Rights and Wellbeing Division. Legal Act. Edinburgh, Scotland: CFD.

Creswell, J. W., \& Miller, D. L. (2000). Determining validity in qualitative inquiry. Theory into practice, 39, 124-130. doi: 10.1207/s15430421 tip3903_2

De Boer, A., Pijl, S. J., \& Minnaert, A. (2011). Regular primary schoolteachers' attitudes towards inclusive education: A review of the literature. International journal of inclusive education, 15, 331-353. doi: 10.1080/13603110903030089

Domitrovich, C. E., Bradshaw, C. P., Greenberg, M. T., Embry, D., Poduska, J. M., \& Ialongo, N. S. (2010). Integrated models of school-based prevention: logic and theory. Psychology in the Schools, 47, 71-88. doi: 10.1002/pits.20452

EADSNE [European Agency for Development in Special Needs Education] (2012). Profile of inclusive teachers. Odense, Denmark: EADSNE.

Eisenman, L. T., Pleet, A. M., Wandry, D., \& McGinley, V. (2011). Voices of special education teachers in an inclusive high school: Redefining responsibilities. Remedial and Special Education, 32, 91-104. doi:10.1177/0741932510361248

Farrell, M. (2010). Debating special education. New York, NY: Routledge. 
Florian, L. (2012). Preparing teachers to work in inclusive classrooms: Key lessons for the professional development of teacher educators from Scotland's inclusive practice project. Journal of Teacher Education, 63, 275-285. doi:10.1177/0022487112447112

Florian, L. (2014). What counts as evidence of inclusive education? European Journal of Special Needs Education, 29, 286-294. doi: 10.1080/08856257.2014.933551

Florian, L., \& Black-Hawkins, K. (2011). Exploring inclusive pedagogy. British Educational Research Journal, 37, 813-828. doi:10.1080/01411926.2010.501096

Florian, L., \& Rouse, M. (2009). The inclusive practice project in Scotland: Teacher education for inclusive education. Teaching and teacher education, 25, 594-601. doi: 10.1016/j.tate.2009.02.003

Florian, L., \& Spratt, J. (2013). Enacting inclusion: A framework for interrogating inclusive practice. European Journal of Special Needs Education, 28, 119-135. doi: $10.1080 / 08856257.2013 .778111$

Forlin, C., \& Chambers, D. (2011). Teacher preparation for inclusive education: Increasing knowledge but raising concerns. Asia-Pacific Journal of Teacher Education, 39, 1732. doi: 10.1080/1359866X.2010.540850

Göransson, K., \& Nilholm, C. (2014). Conceptual diversities and empirical shortcomings-a critical analysis of research on inclusive education. European Journal of Special Needs Education, 29, 265-280. doi:10.1080/08856257.2014.933545

Gwernan-Jones, R., \& Burden, R. L. (2010). Are they just lazy? Student teachers' attitudes about dyslexia. Dyslexia, 16, 66-86. doi: 10.1002/dys.393

Hemmingsson, H., Gustavsson, A., \& Townsend, E. (2007). Students with disabilities participating in mainstream schools: Policies that promote and limit teacher and therapist cooperation. Disability \& Society, 22, 383-398.

doi:10.1080/09687590701337892 
Hillier, S. L., Civetta, L., \& Pridham, L. (2010). A systematic review of collaborative models for health and education professionals working in school settings and implications for training. Education for Health, 23, 393-406.

Hunter, C., Maciver, D., Howden, S., Forsyth, K., Adamson, A., \& Bremner, L. (2013). Identification of a common language describing paediatric physiotherapy practice for children with additional support needs, to support communication with those outside the physiotherapy profession. Physiotherapy, 99, 84-91. doi:

10.1016/j.physio.2011.12.001

Kalambouka, A., Farrell, P., Dyson, A., \& Kaplan, I. (2007). The impact of placing pupils with special educational needs in mainstream schools on the achievement of their peers. Educational Research, 49, 365-382. doi:10.1080/00131880701717222

Kauffman, J. M. \& Landrum, T. J. (2009). Characteristics of emotional and behavioral disorders of children and youth. Upper Saddle River, NJ: Prentice Hall.

Kielhofner, G. (2008). Model of human occupation: Theory and application (4 ${ }^{\text {th }}$ ed.). Philadelphia, PA: Lippincott Williams \& Wilkins.

Koster, M., Nakken, H., Pijl, S. J., \& van Houten, E. (2009). Being part of the peer group: A literature study focusing on the social dimension of inclusion in education. International Journal of Inclusive Education, 13, 117-140. doi:10.1080/13603110701284680?src=recsys

Law, J., Rush, R., Anandan, C., Cox, M., \& Wood, R. (2012). Predicting language change between 3 and 5 years and its implications for early identification. Pediatrics, 130, e132-e137. doi:10.1542/peds.2011-1673. Epub 2012 Jun 11.

Lehohla, M., \& Hlalele, D. (2012). Inclusive classrooms: An ecosystemic perspective. Journal of Human Ecology, 37, 189-201. doi:10.1080/09709274.2012.11906464 
Lindsay, G. (2007). Educational psychology and the effectiveness of inclusive education/mainstreaming. British Journal of Educational Psychology, 77, 1-24. doi: $10.1348 / 000709906 X 156881$

MacFarlane, K., \& Woolfson, L. M. (2013). Teacher attitudes and behavior toward the inclusion of children with social, emotional and behavioral difficulties in mainstream schools: An application of the theory of planned behavior. Teaching and teacher education, 29, 46-52. doi: 10.1016/j.tate.2012.08.006

Maciver, D., Hunter, C., Adamson, A., Grayson, Z., Forsyth, K. \& McLeod, I. (2018). Supporting successful inclusive practices for learners with disabilities in high schools:a multisite, mixed method collective case study. Disability and Rehabilitation, 40, 1708-1717. doi: 10.1080/09638288.2017.1306586

McLeskey, J., \& Waldron, N. L. (2011). Educational programs for elementary students with learning disabilities: Can they be both effective and inclusive?. Learning Disabilities Research \& Practice, 26, 48-57. doi:10.1111/j.1540-5826.2010.00324.x

Michie, S., Johnston, M., Francis, J., Hardeman, W., \& Eccles, M. (2008). From theory to intervention: mapping theoretically derived behavioural determinants to behaviour change techniques. Applied psychology, 57, 660-680. doi:10.1111/j.14640597.2008.00341.x

Morningstar, M. E., Shogren, K. A., Lee, H. \& Born, K. (2015). Preliminary lessons about supporting participation and learning in inclusive classrooms. Research and Practice for Persons with Severe Disabilities, 40, 192-210. doi:10.1177/1540796915594158

NESSE [Network of Experts in Social Sciences of Education and Training] (2012). Education and Disability/special Needs: Policies and Practices in Education, Training and Employment for Students with Disabilities and Special Education Needs in the EU. Brussels, Belgium: EC. 
Oh-Young, C., \& Filler, J. (2015). A meta-analysis of the effects of placement on academic and social skill outcome measures of students with disabilities. Research in developmental disabilities, 47, 80-92. doi:10.1016/j.ridd.2015.08.014. Epub 2015 Sep 4

Oliver, M. (2013). The social model of disability: thirty years on. Disability \& society, 28, 1024-1026. doi: 10.1080/09687599.2013.818773

Patton, M. Q. (1990). Qualitative evaluation and research methods (2nd ed.). Thousand Oaks, CA: Sage Publications.

Pereira, E., Cour, K. L., Jonsson, H., \& Hemmingsson, H. (2010). The participation experience of children with disabilities in Portuguese mainstream schools. British Journal of Occupational Therapy, 73, 598-606.

doi:10.4276/030802210X12918167234244

Quinn, S., \& Mullally, C. (2008). An exploration of occupational therapists' perceptions of their role in educational settings in Ireland. Irish Journal of Occupational Therapy, 36, 4-13. doi:10.1080/19411241003684274? src=recsys

Raghavendra, P., Olsson, C., Sampson, J., Mcinerney, R., \& Connell, T. (2012). School participation and social networks of children with complex communication needs, physical disabilities, and typically developing peers. Augmentative and Alternative Communication, 28, 33-43. doi:10.3109/07434618.2011.653604

Ruijs, N. M., \& Peetsma, T. T. (2009). Effects of inclusion on students with and without special educational needs reviewed. Educational Research Review, 4, 67-79. doi:10.1016/j.edurev.2009.02.002

Scottish Government (2010a). Summary statistics for schools in Scotland. Retrieved from: http://www.gov.scot/Topics/Statistics/Browse/School$\underline{\text { Education/Summarystatsforschools }}$ 
Scottish Government (2010b). Scottish Index of Multiple deprivation. Retrieved from: http://www.gov.scot/Topics/Statistics/SIMD

Scottish Government (2012). Getting it Right for Every Child (GIRFEC). Edinburgh, Scotland: Scottish Government.

Shogren, K.A., McCart, A.B., Lyon, K.J., Wayne S. \& Sailor, W.S. (2015). All means all: building knowledge for inclusive schoolwide transformation. Research and Practice for Persons with Severe Disabilities, 40, 173-191. doi:10.1177/1540796915586191

Shogren, K.A. \& Wehmeyer, M.L. (2014). Using the core concepts framework to understand three generations of inclusive practices. Inclusion, 2, 237-247. doi:10.1352/2326$6988-2.3 .237$

Simpson, R. L., Peterson, R. L., \& Smith, C. R. (2011). Critical educational program components for students with emotional and behavioral disorders: Science, policy, and practice. Remedial and Special Education, 32, 230-242. doi:10.1177/0741932510361269

Slee, R. (2011). The irregular school: Exclusion, schooling and inclusive education. New York, NY: Routledge

Slee, R. (2014). Discourses of Inclusion and Exclusion: drawing wider margins. Power and Education, 6, 7-17. doi:10.2304/power.2014.6.1.7

Szumski, G., \& Karwowski, M. (2014). Psychosocial functioning and school achievement of children with mild intellectual disability in Polish special, integrative, and mainstream schools. Journal of Policy and Practice in Intellectual Disabilities, 11, 99-108. doi: 10.1111/jppi.12076

Taylor, B., Jick, H., \& MacLaughlin, D. (2013). Prevalence and incidence rates of autism in the UK: time trend from 2004-2010 in children aged 8 years. BMJ open, 3, e003219. doi:10.1136/bmjopen-2013-003219 
Thelen, E. (2005). Dynamic systems theory and the complexity of change. Psychoanalytic Dialogues, 15, 255-283. doi: 10.1080/10481881509348831

Tiwari, A., Das, A., \& Sharma, M. (2015). Inclusive education a "rhetoric" or "reality"? Teachers' perspectives and beliefs. Teaching and Teacher Education, 52, 128-136. doi: 10.1016/j.tate.2015.09.002

UNICEF [United Nations International Children's Emergency Fund] (2013). The State of the World's Children 2013: Children with Disabilities. New York, NY: UNICEF.

Whitehouse, A. J., Watt, H. J., Line, E. A., \& Bishop, D. V. (2009). Adult psychosocial outcomes of children with specific language impairment, pragmatic language impairment and autism. International Journal of Language \& Communication Disorders, 44, 511-528. doi:10.1080/13682820802708098

Whittemore, R., Chase, S. K., \& Mandle, C. L. (2001). Validity in qualitative research. Qualitative health research, 11, 522-537. doi: 10.1177/104973201129119299 WHO [World Health Organisation]. (2007). International Classification of Functioning, Disability and Health: Children and Youth version. Geneva, Switzerland: WHO. 